\title{
Health risk analysis of the environmental burden
}

\author{
M. Č́slavský ${ }^{1}$, F. Božek ${ }^{2} \&$ A. Bumbová ${ }^{2}$ \\ ${ }^{1}$ GEOtest, a. s., Brno, Czech Republic \\ ${ }^{2}$ Civil Protection Department, University of Defence, Czech Republic
}

\begin{abstract}
The paper presents the results of risk assessment of the area of the Zetor Company, on which the environmental burden of chromium occurs, resulting from the operation of a former electroplating plant. The concentration of chromium was determined by the method of inductively coupled plasma atomic emission spectrometry. We have calculated non-carcinogenic risks for workers provided that the premises are intended for industrial use and for children aged six years and younger and adults provided that the premises are used as a residential zone. We have considered as exposure scenarios accidental ingestion of soils and contamination from constructional elements, inhalation of air containing dust with an absorbed contaminant and accidental ingestion of groundwater. We have also evaluated a genotoxic risk resulting from inhalation of contaminated air by employees.
\end{abstract}

Keywords: dermal contact, exposure, chromium, ingestion, inhalation, carcinogenic risk, nun-carcinogenic risk.

\section{Introduction}

Contaminated soil, rock environment and groundwater pose a significant problem in environmental protection. In many cases, environmental burdens are a source of the unacceptable risk for the health of the population, groundwater and surface water, natural resources as well as other environmental components and often preclude the use of a site and the development of activities in a region.

The need for high financial sums to remove environmental burdens and limited funds on the other hand require an integrated system of assessment and 
remedy of environmental burdens focused on the maximum effectiveness of remediation being carried out.

The objective of the risk analysis resulting from environmental burdens of an area is to characterize the current and potential risks for the environment, the health of the population and their property. The outcomes of risk assessment are the basis for the final decision on the necessity of the area remediation. If remediation is necessary, risk assessment serves for the proposal of a technology and the determination of target parameters of the future remediation so that the need for material, human and particularly financial resources is minimized.

The submitted paper is focused on risk assessment of the released western part of the Zetor, a.s company area, which is situated in city Brno, Czech Republic. The outcomes of risk assessment have proved as the critical risk the contamination of a part of the released area by chromium, above all at the sites where an electroplating plant was situated in the past. Remedial measures have been proposed for these sites.

\section{The theoretical part}

Chromium is the twenty-first most abundant element in Earth's crust with an average concentration of $100 \mathrm{ppm}$ (Emsley [1]). Chromium compounds are found in the environment, due to erosion of chromium-containing rocks and can be distributed by volcanic eruptions. The concentrations in soil range between 1 and $3 \times 10^{3} \mathrm{mg} \mathrm{kg}^{-1}$, in sea water $5-800 \mu \mathrm{g} \mathrm{dm}^{-3}$, and in rivers and lakes from 26 $\mu \mathrm{g} \mathrm{dm}^{-3}$ to $5.2 \mathrm{mg} \mathrm{dm}^{-3}$. The relation between $\mathrm{Cr}(\mathrm{III})$ and $\mathrm{Cr}(\mathrm{VI})$ strongly depends on $\mathrm{pH}$ and oxidative properties of the location, but in most cases, the $\mathrm{Cr}(\mathrm{III})$ is the dominating species (Kotas and Stasicka [4]), although in some areas the groundwater can contain up to $39 \mu \mathrm{g}$ of total chromium, of which $30 \mu \mathrm{g}$ is present as $\mathrm{Cr}(\mathrm{VI})$ (Gonzalez et al. [3]). Chromium is mined as chromite $\left(\mathrm{FeCr}_{2} \mathrm{O}_{4}\right)$ ore. The small chromium quantities contribute to the colouration of emerald and ruby gemstones.

Chromium may exist in several chemical forms and valence states in the environment. The most commonly occurring valence states are chromium metal(0), trivalent $\mathrm{Cr}(\mathrm{III})$, and hexavalent $\mathrm{Cr}(\mathrm{VI})$. Hexavalent chromium is the major toxic contaminant, which enters the environment through various industrial operations. The potential sources of hexavalent chromium wastes are effluents from metallurgy, electroplating, leather tanning, textile dyeing, paint, ink, and aluminium manufacturing industries as well as a variety of niche uses (Bhattacharyya and Gupta [2], Verma et al. [9]).

Hexavalent chromium is much more toxic than trivalent chromium, for both acute and chronic exposures. Shortness of breath, coughing, and wheezing were reported in cases where an individual inhaled very high concentrations of chromium trioxide. Other effects noted from acute inhalation exposure to very high concentrations of chromium(VI) include gastrointestinal and neurological effects, while dermal exposure causes skin burns in humans. Ingestion of high amounts causes gastrointestinal effects in humans and animals, including abdominal pain, vomiting, and hemorrhage (ATSDR [10]). 
Chronic inhalation exposure to chromium(VI) in humans results in effects on the respiratory tract, with perforations and ulcerations of the septum, bronchitis, decreased pulmonary function, pneumonia, asthma, and nasal itching and soreness reported. The high levels by inhalation or oral exposure may produce effects on the liver, kidney, gastrointestinal and immune systems, and possibly the blood. Dermal exposure may cause contact dermatitis, sensitivity, and ulceration of the skin ATSDR [10]. The U.S. EPA estimated for chronic exposure oral reference dose $R f D=3 \times 10^{-3} \mathrm{mg} \mathrm{kg}^{-1}$ day $^{-1}$ and inhalation reference concentration $R f C=8 \times 10^{-6} \mathrm{mg} \mathrm{m}^{-3}$ USEPA [14].

Chromium(VI) is carcinogenic to both humans and animals (Mungasavalli et al. [6]). Epidemiological studies of workers have clearly established that inhaled chromium(VI) is a human carcinogen, resulting in an increased risk of lung cancer. Although workers were exposed to both chromium(III) and chromium(VI) compounds, only chromium(VI) has been found to be carcinogenic in animal studies. Animal studies have shown chromium(VI) to cause lung tumours via inhalation exposure USEPA [14]. Strong exposure causes cancer in the digestive tract and lungs and may cause gastric pain, nausea, vomiting, severe diarrhea, and hemorrhage (Mohanty et al. [5]). That is why chromium(VI) is classified as Group A, known as a human carcinogen by the inhalation route of exposure. Carcinogenicity by the oral and dermal routes of exposure cannot be determined and is classified as Group D not classifiable as to human carcinogenicity. An inhalation unit risk was calculated as the estimate of $I U R=1.2 \times 10^{-2} \mathrm{~m}^{3} \mu \mathrm{g}^{-1}$ USEPA [14].

The maximum permissible limits in wastewater and potable water are $1.0 \mathrm{mg} \mathrm{dm}^{-3}$ and $0.05 \mathrm{mg} \mathrm{dm}^{-3}$ for chromium(VI), respectively (Park et al. [7]).

Hexavalent chromium compounds are often found in soil and groundwater at abandoned industrial sites, now needing environmental cleanup and remediation per the treatment of brownfield land (Seaman et al. [8]).

\section{The methods used}

Investigation work was carried out in compliance with a binding guideline MoE [11]. Sampling work followed an applicable methodology MoE [12].

The determination of chromium was made by the method inductively coupled plasma atomic emission spectrometry with help of the device THERMOFISHER ICAP6000. The detection limit of the determination of chromium is units of $\mu \mathrm{g} \mathrm{dm}^{-3}$ in pure waters, tens of $\mu \mathrm{g} \mathrm{dm}^{-3}$ in contaminated waters and tens of $\mu \mathrm{g} \mathrm{kg}^{-1}$ or less in soils. The pre-treatment of contaminated water is made by pressure mineralization in a microwave oven. The determination in soil is made in an aqueous extract or after total pressure decomposition in nitric acid $\left(\mathrm{HNO}_{3}\right)$ mixed with hydrogen peroxide $\left(\mathrm{H}_{2} \mathrm{O}_{2}\right)$.

The risk assessment method was used in compliance with the legal system of the Czech Republic MoE [11] while observing the USEPA method [13, 16]. The calculation was made for the selected exposure scenarios comprising the non-carcinogenic and genotoxic effects of $\mathrm{Cr}$. 
The necessity for the estimate of the non-carcinogenic risk of contaminants with the threshold effect is the knowledge of the reference dose $R f D\left[\mathrm{mg} \mathrm{kg}^{-1}\right.$ $\left.\mathrm{day}^{-1}\right]$ for accidental ingestion or the inhalation reference concentration $R f C$ [mg $\left.\mathrm{m}^{-3}\right]$. The second prerequisite of risk quantification is the evaluation of exposure. The objective is to estimate the size of chronic daily intake $C D I$. For the accidental ingestion of soil and impurities from constructional elements, $C D I_{I N G, S}\left[\mathrm{mg} \mathrm{kg}^{-1} \mathrm{day}^{-1}\right]$ is expressed by eqn (1); for the accidental ingestion of water, $C D I_{I N G, W}\left[\mathrm{mg} \mathrm{kg}^{-1}\right.$ day $\left.^{-1}\right]$ is given by eqn (2); and for the inhalation of air contaminated by suspended dust, $C D I_{I N H}\left[\mathrm{mg} \mathrm{kg}^{-1}\right.$ day $\left.^{-1}\right]$ can be calculated by eqn (3).

$$
\begin{gathered}
C D I_{I N G, S}=c_{S} \times I R_{I N G, S} \times F I \times E F \times E D \times C F_{1} \times B W^{-1} \times A T^{-1} \\
C D I_{I N G, W}=c_{W} \times I R_{I N G, W} \times E C \times E D \times B W^{-1} \times A T^{-1} \\
C D I_{I N H}=c_{A} \times I R_{I N H} \times E T \times E F \times E D \times B W^{-1} \times A T^{-1}
\end{gathered}
$$

where $c_{S}\left[\mathrm{~g} \mathrm{~kg}^{-1}\right]$ is the average concentration of a contaminant in soil or on/in a constructional element, $c_{W}\left[\mathrm{mg} \mathrm{dm}^{-3}\right]$ is the concentration of a contaminant in water, and $c_{A}\left[\mathrm{mg} \mathrm{m}^{-3}\right]$ is the concentration of a contaminant in the air. The aforementioned concentrations must be obtained by measurement. $I R_{I N G, S}\left[\mathrm{mg}\right.$ day $\left.^{-1}\right]$ represents the amount of randomly ingested soil or a contaminant from a constructional element per day, $F I \in(0 ; 1\rangle$ means a fraction of contaminated sources, $E F$ [day year ${ }^{-1}$ ] is the exposure frequency, $E D$ [year] is exposure duration, $C F_{1}=10^{-3}\left[\mathrm{~kg} \mathrm{~g}^{-1}\right]$ is the conversion factor for converting gram into kilogram, $I R_{I N G, W}\left[\mathrm{dm}^{3}\right.$ incident $\left.^{-1}\right]$ is the amount of accidentally ingested contaminated water per year, $E C$ [incident year $\left.{ }^{-1}\right]$ is the frequency of exposure, $I R_{I N H}\left[\mathrm{~m}^{3} \mathrm{~h}^{-1}\right]$ is the inhaled amount of air, $E T\left[\mathrm{~h}\right.$ day $\left.^{-1}\right]$ is the exposure time, $B W[\mathrm{~kg}$ ] is the average body weight, and finally $A T$ [day] is the time during which the concentrations of contaminants $c_{S}, c_{W}$ and $c_{A}$ can be considered as constant.

To convert $C D I_{I N H}\left[\mathrm{mg} \mathrm{kg}^{-1}\right.$ day $\left.^{-1}\right]$ into $A D D\left[\mathrm{mg} \mathrm{m}^{-3}\right]$, was used the eqn (4):

$$
A D D=C D I_{I N H} \times B W \times I R_{I N H}^{-1} \times C F_{2}
$$

in which $C F_{2}=24^{-1}$ [day. $\mathrm{h}^{-1}$ ] is the conversion factor for converting hours into days and the other symbols have the same significance as in eqn (3).

For characterizing a non-carcinogenic risk, there is the hazard quotient $H Q$, which is the ratio of the exposure dose expressed as $C D I$ to the reference dose $R f D$ or concentration $R f C$, respectively:

$$
\begin{aligned}
& H Q=C D I \times R f D^{-1} \\
& H Q=A D D \times R f C^{-1}
\end{aligned}
$$


If $H Q \leq 1$, the risk is acceptable; if $H Q \in(1 ; 4\rangle$, the risk is tolerable; and if $H Q>4$, the risk is unacceptable and remedial measures must immediately be implemented.

The individual excess lifetime cancer risk $E L C R$ by inhalation of contaminated air expresses incidence of cancer above the general average and serves for characterizing a carcinogenic risk. ELCR can be quantified by eqn (7), in which $I U R\left[\mathrm{~m}^{3} \mu \mathrm{g}^{-1}\right]$ denotes the inhalation unit risk.

$$
E L C R=1-e^{-(A D D \times I U R)}
$$

In the world it is agreed that the target value of the acceptability of the individual genotoxic risk is $E L C R \leq 10^{-6}$. If $E L C R \in\left(10^{-6} ; 10^{-4}\right)$, the individual risk is still tolerable, and if $E L C R \geq 10^{-4}$, the risk is unacceptable and it is necessary to immediately implement remedial measures.

\section{Results and discussion}

The dominant production programme of the Zetor, a.s. company and its predecessors, where the released recognized area is contaminated, was the manufacture of tractors. The production of metallurgical semi-finished products, castings and forgings along with preparations and tools for machining was supplementary. The premises belonging to the company is located in the Brno City, Czech Republic. It is made up of a number of production buildings, handling areas and service roads. Open, unbuilt areas and service roads are largely of concrete or asphalt and are mostly provided with a sewer for catchment and discharge of precipitation water.

In 2005, the restructured premises Zetor New were opened, situated in the eastern half of the original company. The area in the western part was released for sale and re-use. Mainly large production halls and several smaller buildings, assembled metal plate halls, mobile cabins or wooden constructions are situated there. In the released part of the Zetor, a.s. company the updating of risk assessment was made in 2006. Within exploration works, the contamination of constructional elements, soils and groundwater was specified.

The significant contaminants identified within exploration works included non-polar extractable substances documenting the presence of petroleum substances. Furthermore, the contamination of soils and groundwater by chlorinated ethylenes, in particular by tetrachloroethylene, trichloroethylene and cis-1,2-dichlorethylene, was detected. Also, polycyclic aromatic hydrocarbons, with prevailing benzo[a]pyrene, and trace metals, mainly chromium and lead, were also found. The preliminary risk assessment has proved that the highest critical health risk to the area is caused by a chromium burden deriving from the operation of the electroplating plant. This paper deals with the quantitative assessment of the risk resulting from the presence of chromium.

The operation of the former electroplating plant took place in a hall where a tool shop and an engineering shop were located. The tool shop supplied special 
preparations and tools. A part of the tool shop was also a chrome-plating plant for the electroplating finishing of metal tools. One of the chromium sewer branches leads from the electroplating plant to a neutralization station.

The contamination by chromium was already manifested visually as the efflorescence on plasters and in soil outside of the hall. The maximum concentration of chromium on the floor of the chrome-plating plant was $18.6 \mathrm{~g} \mathrm{~kg}^{-1}$ of dry matter and in the plaster $2.1 \mathrm{~g} \mathrm{~kg}^{-1}$ of dry matter. The highest concentration of chromium in the underlying soils was determined in a value of $10.7 \mathrm{mg} \mathrm{kg}^{-1}$ of dry matter and in the air $186 \mu \mathrm{g} \mathrm{m}^{-3}$. In borehole near the hall, a local hotspot of contamination by chromium was detected, with a concentration of $1.32 \mathrm{mg} \mathrm{dm}^{-3}$. The above-given concentrations were taken as the basis for risk calculation.

The calculation of the exposure of the studied contaminant, in the form of chronic daily intake $C D I$, was made by the equations specific for the individual exposure scenarios which are based on the prediction models of the USEPA. The following exposure scenarios were considered:

a) In the industrial premises, was quantified the non-carcinogenic risk for workers in connection with the consequences of contact with contaminated soil and constructional elements during remediation work associated with earthwork and demolition of buildings. The exposure scenarios connected with accidental ingestion and inhalation of air contaminated by dust with absorbed hexavalent chromium were evaluated for both the types of the contaminated media. Also, the consequence of accidental ingestion of groundwater exploited for sanitary facilities (rest rooms, showers) and for technological purposes was assessed. Of carcinogenic risks, exclusively the risk resulting from inhalation of contaminated air was evaluated.

b) For the case of residential use of the area, the non-carcinogenic risk for adults and children was monitored in connection with the potential ingestion of contaminated soil when working in small gardens. This danger mainly relates to children. In the hypothetical residential zone, neither the risk resulting from inhalation of air contaminated with dust nor the risk resulting from contaminated constructional elements was evaluated. It is namely possible to suppose that these types of risks are negligible. Moreover, have been assessed the consequence of accidental ingestion of groundwater exploited from private wells for watering small gardens and for washing hands and for showering.

Non-carcinogenic dermal risks were not assessed because these kinds of risks mostly reach lower values in comparison with risks resulting from accidental ingestion of all assessed polluted media. Neither genotoxic risks resulting from accidental consumption of a contaminant or from dermal contact with it were assessed because the absorption of hexavalent chromium through these exposure pathways has no carcinogenic effects USEPA [14].

For the calculations of hazard quotients $H Q$, were used the values of $R f D=3 \times 10^{-3} \mathrm{mg} \mathrm{kg}^{-1} \mathrm{day}^{-1}$ and $R f C=8 \times 10^{-6} \mathrm{mg} \mathrm{m}^{-3}$ and, similarly for the calculation of $E L C R$, we used the value of $I U R=1.2 \times 10^{-2} \mathrm{~m}^{3} \mu \mathrm{g}^{-1}$, all of them 
presented by the USEPA [14]. The results are summed up for non-carcinogenic risks in table 1 and for carcinogenic risks in table 2.

The presented outcomes show that neither workers nor the potential population is threatened by the increase in malignant tumours diseases in spite of the $E L C R$ target value is set up ELCR $=10^{-6}$ USEPA [15].

It has been found out that it is necessary to reduce the non-carcinogenic risk associated with ingestion of contaminated soil for workers and especially children in case of the residential use of recognized area. The risks for workers resulting from inhalation of air with contaminated dust are tolerable. The application of individual protective means may reduce these types of risks relevantly. The risk assessment has proved explicitly that the remediation of groundwater it is not necessary to carry out neither the area is released for needs of residential use.

Table 1: Non-carcinogenic risks.

\begin{tabular}{|l|l|l|c|c|c|}
\hline \multirow{4}{*}{ Land use } & $\begin{array}{c}\text { Source of } \\
\text { contamination }\end{array}$ & $\begin{array}{c}\text { Hazard } \\
\text { quotient }\end{array}$ & Workers & Adults & Children \\
\hline \multirow{5}{*}{ Industrial } & $\begin{array}{l}\text { Constructional } \\
\text { elements }\end{array}$ & $H Q_{I N G}$ & $2.18 \mathrm{E}+00$ & - & - \\
\cline { 2 - 6 } & \multirow{2}{*}{ Soils } & $H Q_{I N H}$ & $2.99 \mathrm{E}+00$ & - & - \\
\cline { 2 - 6 } & Water & $H Q_{I N G}$ & $\mathbf{5 . 0 0 E}+\mathbf{0 0}$ & - & - \\
\cline { 2 - 7 } & $H Q_{I N H}$ & $1.72 \mathrm{E}+00$ & - & - \\
\hline \multirow{2}{*}{ Residential } & Soils & $H Q_{I N G}$ & $4.30 \mathrm{E}-01$ & - & - \\
\cline { 2 - 7 } & Groundwater & $H Q_{I N G}$ & - & $5.80 \mathrm{E}-01$ & $\mathbf{1 . 2 7 E + 0 1}$ \\
\hline
\end{tabular}

Table 2: $\quad$ Carcinogenic risks.

\begin{tabular}{|l|l|c|c|c|c|}
\hline Land use & $\begin{array}{c}\text { Source of } \\
\text { contamination }\end{array}$ & $\begin{array}{c}\text { Excess } \\
\text { Lifetime } \\
\text { Risk } \\
\text { Cancer }\end{array}$ & Workers & Adults & Children \\
\hline \multirow{2}{*}{ Industrial } & $\begin{array}{l}\text { Constructional } \\
\text { elements }\end{array}$ & $E L C R$ & $4.09 \mathrm{E}-06$ & - & - \\
\cline { 2 - 7 } & Soils & $E L C R$ & $2.36 \mathrm{E}-06$ & - & - \\
\hline
\end{tabular}

Ecological risks have not been addressed because of the financial and time deficit. However, it can be assumed that in the premises of the studied Zetor, a.s. company unacceptable ecological risks will not occur because no indigenous ecosystems are found there. Valuable biotopes of one national nature monument and one nature monument, that are located near the site of contamination, can be threatened rather by emissions from industrial sources and traffic. Neither toxicological tests of groundwater from boreholes on the defined area indicate ecological risks as well. 
The input data used for the quantification of risks imply a certain degree of uncertainties which have undoubtedly influenced the results of estimate. The uncertainties are particularly as follows:

a) The concentrations of chromium were determined with the degree of uncertainty $\pm 35 \%$.

b) For the carcinogenic and non-carcinogenic risks assessment, the maximum concentrations detected in all media were used, which shows that the risks will be rather overestimated from this point of view.

c) For the calculation of risk, the concentrations comprising the content of all chromium were applied, although the risks associated with trivalent chromium are considered as relevantly lower (almost three orders).

d) Most of the exposure factors were also rather overestimated in risk quantification as well.

e) The validity of the oral reference dose $R f D$, the inhalation reference concentration $R f C$ and the inhalation unit risk IUR, taken from the USEPA databases, is evaluated by this institution itself as "low" or "medium" USEPA [14].

f) The calculations of chronic daily intakes $C D I$ in the assessment are based on the assumption of the full absorption of harmful substances in the human organism, which is also not too realistic in practice.

g) The interaction between $\mathrm{Cr}(\mathrm{VI})$ and other compounds present in the analysed samples was not taken into consideration either, which also reduces the validity of the achieved results.

In order to reduce or almost eliminate the identified critical risks, we have proposed the implementation of the following countermeasures:

a) Demolition of the building of the old electroplating plant;

b) Demolition of the above-ground part of the hall, the floors and the underground parts of the hall;

c) The disposal of the sewer piping and the excavation of contaminated soil along the branch of the chromium sewerage;

d) Excavation of contaminated soils below the foundations of the old electroplating plant (about $\left.100 \mathrm{~m}^{3}\right)$;

e) Liquidation of generated wastes in compliance with the applicable legislation and relevant guidelines.

\section{Conclusion}

The outcomes of risk assessment have confirmed the conclusions of previously conducted exploration work on the state of contamination of the rock environment (soil and groundwater) by $\mathrm{Cr}$ at the studied site. The risks for workers resulting from contact with contaminated soil have been found as unacceptable. The still higher risk would be posed to the residential use of the land when children could come into contact with contaminated soil. The risks for workers that are associated with inhalation of air with contaminated dust and at the same time with accidental ingestion of contaminated constructional elements were quantified as tolerable ones. 
Based on the results of risk assessment, it is necessary to start on efficient remedial measures which would lead to the achievement of a socially acceptable level of risk at the recognized area. These remedial measures can be implemented to a different extent and intensity, which, however, is reflected in the determination of the needed time and the amount of funds for remediation.

It has been recommended a scenario which would include the demolition of the former electroplating plant and the excavation of contaminated soils beneath its foundations with the subsequent removal of generated wastes in compliance with valid legislation. The construction pits will be backfilled with inert material that will be subsequently compacted.

\section{References}

[1] Emsley, J. Nature's Building Blocks: An A-Z Guide to the Elements. Oxford: Oxford University Press. pp. 495-498. ISBN 0198503407. 2001.

[2] Bhattacharyya, K. G. \& Gupta, S. Sen. Adsorption of Chromium(VI) from Water by Clays. Industrial Engineering and Chemistry Research, 45(21), pp. 7232-7240, 2006.

[3] Gonzalez, A. R., Ndung'u, K. \& Flegal, A. R. Natural Occurrence of Hexavalent Chromium in the Aromas Red Sands Aquifer, California. Environmental Science and Technology, 39(15), pp. 5505-5511, 2005.

[4] Kotas, J. \& Stasicka, Z. Chromium Occurrence in the Environment and Methods of Its Speciation. Environmental Pollution, 107(3), pp. 263-283, 2000 .

[5] Mohanty, K. et al. Removal of Chromium(VI) from Dilute Aqueous Solutions by Activated Carbon Developed from Terminalia Arjuna Nuts Activated with Zinc Chloride. Chemical Engineering Science, 60(11), pp. 3049-3059, 2005.

[6] Mungasavalli, D. P., Viraraghavan, T. \& Jin, Y. Ch. Biosorption of Chromium from Aqueous Solutions by Pretreated Aspergillus Niger: Batch and Column Studies. Colloids and Surfaces A: Physicochemical Engineering Aspects, 301(1-3), pp. 214-223, 2007.

[7] Park, D., Yun, Y, S. \& Park, J. Studies on Hexavalent Chromium Biosorption by Chemically Treated Biomass of Ecklonia sp. Chemosphere, 60(10), pp. 1356-1364, 2005.

[8] Seaman, J. C., Bertsch, P. M. \& Schwallie, L. In Situ Cr(VI) Reduction within Coarse-Textured, Oxide-Coated Soil and Aquifer Systems Using Fe(II) Solutions. Environ. Sci. Technol., 33(6), pp. 938-944, 1999.

[9] Verma, A., Chakraborty, S. \& Basu, J. K. Adsorption Study of Hexavalent Chromium Using Tamarind Hull-Based Adsorbents. Separation and Purification Technology, 50(3), pp. 336-341, 2006.

[10] Agency for Toxic Substances and Disease Registry (ATSDR). Toxicological Profile for Chromium. Atlanta, GA: U.S. Public Health Service. 1998. 
[11] Ministry of Environment (MoE). Methodical Instructions MoE No 12 for the Risk Analysis of Contaminated Area. MoE Bulletin, XV, article 9, pp. 1-41, 2005.

[12] Ministry of Environment (MoE). Methodical Instructions MoE No 13 for Exploration of Contaminated Area. MoE Bulletin, XV, article 9, pp. 42-76, 2005.

[13] United States Environmental Protection Agency (USEPA). Guidelines for Ecological Risk Assessment. Washington, DC: USEPA, Risk Assessment Forum, EPA/630/R095/002F.

[14] United States Environmental Protection Agency (USEPA). Integrated Risk Information System (IRIS) on Chromium VI. Office of Research and Development, Online. http://www.epa.gov/iris/subst/0144.htm

[15] United States Environmental Protection Agency (USEPA). Integrated Risk Information System (IRIS), Office of Research and Development, Online. http://www.epa.gov/iris/subst/

[16] United States Environmental Protection Agency (USEPA). Risk Assessment Guidance for Superfund (RAGS), Volume I: Human Health Evaluation Manual, Waste and Cleanup Risk Assessment, Online. www.epa.gov/swerrims/riskassessment/ragse/index.htm 